\title{
A Brazilian cohort of patients with Tourette's syndrome
}

\author{
Francisco Cardoso, Cláudio C M Veado, José Teotonio de Oliveira
}

\begin{abstract}
The clinical features of 32 patients (24 males) with Tourette's syndrome in Brazil were studied. The mean age at onset was $7 \cdot 1$ years, tics being the first symptom in $71 \%$ and hyperactivity in $29 \%$. Blinking, grimacing, and shoulder elevation were the most common motor tics and sniffing, throat clearing, and grunting noises, the most frequent vocal tics. Coprolalia was present in $28 \%$, echolalia in $16 \%$, palilalia in $9 \%$, and copropraxia in $25 \%$ of patients. Attention deficit and hyperactivity disorder was diagnosed in $63 \%$, and obsessive compulsive behaviour in $44 \%$ of patients. In $84 \%$ of patients there was a family history of tics whereas attention deficit and hyperactivity disorder and obsessive compulsive behaviour were respectively present in relatives of $19 \%$ and $53 \%$ of the patients studied. These data suggest that Tourette's syndrome in Brazil is not clinically different from other countries, supporting the notion that genetic factors play the most important part in its aetiology.
\end{abstract}

$(F$ Neurol Neurosurg Psychiatry 1996;60:209-212)

Keywords: tic; Tourette's syndrome; attention deficit and hyperactivity disorder; obsessive compulsive disorder

Tourette's syndrome is a disorder characterised by a combination of motor and vocal tics with onset usually in the first two decades of life, lasting more than one year and causing considerable impairment in social, occupational, or other important areas of functioning. ${ }^{1}$ Many patients display associated behavioural disturbances, mainly attention deficit and hyperactivity disorder and obsessive compulsive behaviour. ${ }^{2}$ Although in his original description Gilles de La Tourette emphasised the hereditary nature of the syndrome, ${ }^{3}$ only recently has evidence been gathered suggesting that the most likely mode of transmission for Tourette's syndrome and related conditions is autosomal dominant inheritance. ${ }^{4}$ Recent epidemiological studies indicate a prevalence ranging from 3 to $10 / 1000$, showing that Tourette's syndrome is more common than previously thought. ${ }^{5.9}$ Mild intensity of Tourette's syndrome in most patients, a tendency to blame psychological factors for tics, and the misconception that coprolalia is essential to the diagnosis may account for Tourette's syndrome being overlooked and underdiagnosed.

Large series of patients with Tourette's syndrome from the northern hemisphere have been described, ${ }^{10-12}$ but there are only a few reports on the syndrome in other areas. ${ }^{13-15} \mathrm{In}$ the present study we describe the clinical characteristics of 32 consecutive patients with Tourette's syndrome seen at a movement disorders clinic in Brazil, to investigate whether the phenomenology of this syndrome varies in different geographic areas.

\section{Patients and methods}

Patients were included in the study if they met the following diagnostic criteria, slightly modified from DSM-IV': a combination of motor and vocal tics with onset in the first two decades of life, lasting more than one year, causing considerable impairment in social, occupational, or other important areas of functioning, and lack of other neurological abnormalities. We also used DSM-IV ${ }^{1}$ modified diagnostic criteria for obsessive compulsive behaviour and attention deficit and hyperactivity disorder. The first was diagnosed when there was a history of obsessions (persistent ideas, thoughts, impulses, or images experienced as intrusive and inappropriate and that cause anxiety or distress); and/or compulsions (repetitive behaviours or mental acts the aim of which is to prevent or reduce anxiety or distress, not to provide pleasure or gratification). The presence of five or more of the following was required for the diagnosis of attention deficit and hyperactivity disorder: failure to give attention to details or making careless mistakes in schoolwork, work, or other activities; difficulty sustaining attention in tasks or playing activities; frequent difficulty organising tasks and activities; easy distractability by extraneous stimuli; failure to follow through on instructions and to finish schoolwork, chores, or duties in the workplace; often leaving seat in classroom or in other situations in which remaining seated is expected; difficulty playing or engaging in leisure activities quietly; talking excessively. 
From July of 1993 to July of 1994, 32 of $504(6 \%)$ patients consecutively seen at the Federal University of Minas Gerais Movement Disorders Clinic (FUMG-MDC), a referral centre for patients with movement disorders in the state of Minas Gerais and neighbouring areas, met the outlined criteria. Patients included in the present study were not referred specifically for investigation of Tourette's syndrome. All patients were examined by one of us (FC). We investigated the age at onset of Tourette's syndrome, the symptoms at onset, the age at onset of tic, the presence of obsessive compulsive behaviour and the age at its onset, the presence of attention deficit and hyperactivity disorder and the age of its onset, the presence of other behavioural disorders, motor and vocal tics, and family history of tics and behavioural abnormalities. All data were entered into a relational database. Two patients with obsessive compulsive behaviour and one with attention deficit and hyperactivity disorder, not able to recall the age at onset of these associated disorders, were excluded from the statistical analysis.

\section{Results}

The mean age of the 24 men and eight women (male:female ratio of $3: 1$ ) at the first visit to the clinic was 22.3 (SD 13.6), range 7-65 years. All patients but one, born of a Brazilian mother in Chile, were natives of Brazil. Five $(16 \%)$ were white and the other $27(84 \%)$ mulatto. The mean age at onset of Tourette's syndrome was $7 \cdot 1$ (SD $4 \cdot 2)$, range $1-19$ years, tics being the first symptom in $22(71 \%)$ and hyperactivity in nine $(29 \%)$. The mean age at onset of tics was $8 \cdot 2$ (SD 3.8), range 3-19 years. Table 1 shows the most frequent motor and vocal tics. Nine patients $(28 \%)$ displayed

Table 1 Motor and vocal tics in a Brazilian cohort of patients $(n=32)$ with Tourette's syndrome

\begin{tabular}{lc}
\hline & No (\%) \\
\hline Motor & \\
Blinking & $28(87)$ \\
Grimacing & $20(62)$ \\
Elevation of shoulders & $16(50)$ \\
Head jerking & $15(46)$ \\
Dystonic tic of the head & $10(31)$ \\
Protrusion of lips & $9(28)$ \\
Copropraxia & $8(25)$ \\
Leg shaking & $7(21)$ \\
Complex gait tics & $6(18)$ \\
Vocal: & $24(75)$ \\
Sniffing & $16(50)$ \\
Throat clearing & $16(50)$ \\
Grunting sounds & $9(28)$ \\
Coprolalia & $5(15)$ \\
Echolalia & $3(9)$ \\
Palilalia & $1(3)$ \\
Barking & \\
\hline
\end{tabular}

coprolalia. Table 2 contains the most common obscenities most often shouted by these patients as well as by patients with Tourette's syndrome from other countries. Abnormal sensations preceded the tics (sensory tics or prodrome) in 10 patients (31\%) whereas only one patient referred to pain associated with tics. This patient had a severe distonic tic of the head, which dislocated the C4-C5 intervertebral disk, producing radiculomyelopathy, as documented by EMG and CT. Only injections of botulinum toxin into the cervical musculature controlled this patient's tic. Fourteen patients (44\%) displayed obsessive compulsive behaviour, with the mean age at onset of $9 \cdot 1$ (SD 3.5), range 5-19 years. Attention deficit and hyperactivity disorder were present in 20 $(63 \%)$ patients, with onset at age 6.9 (SD $6 \cdot 3$ ), range $1-30$ years. Other common behavioural disturbances were sleep disorders (present in 17 patients), depression (diagnosed in 10 patients), and impulse control disorder (recognised in nine patients).

History of tics, obsessive compulsive behaviour, and hyperactivity among first degree relatives was present, respectively, in $27(84 \%)$, $17(53 \%)$, and six (19\%) of the patients. Interestingly, mothers displayed obsessive compulsive behaviour in 12 of the 17 patients with family history of this disturbance. In six patients there was a family history of alcoholism.

\section{Discussion}

In the present study we investigated the clinical features of a Brazilian cohort of patients meeting modified-DSM-IV ${ }^{1}$ criteria for Tourette's syndrome. Overall, our results are similar to those reported on other Tourette's syndrome populations. ${ }^{6}{ }^{15}$ Simple movements (excessive eye blinking, grimacing, shoulder shrugging, and head jerking) and vocalisations such as sniffing, throat clearing, and grunting were the most common tics identified among our patients. Similar results have been reported by Jankovic and Rohaidy ${ }^{8}$ and Comings and Comings ${ }^{11}$ studying, respectively, 112 and 250 patients with Tourette's syndrome in the United States as well as by Lees and colleagues ${ }^{12}$ in their investigation of 53 British patients with Tourette's syndrome. Although we have not rated the severity of our patients' disorder, this finding supports the conclusion that even at specialised centres, where patients are likely to present with more severe symptoms, patients with Tourette's syndrome usually display a mild disease. ${ }^{16}$

Table 2 Comparison of obscenities most commonly spoken by patients with Tourette's syndrome in Brazil and other countries

\begin{tabular}{|c|c|c|c|c|c|}
\hline Brazil Present series & England $^{\prime 2}$ & $U S A^{\prime 8}$ & $\mathcal{F a p a n}^{\prime 9}$ & Spain ${ }^{20}$ & Denmark $^{2 l}$ \\
\hline $\begin{array}{l}\text { Merda (faeces) } \\
\text { Bosta (faeces) } \\
\text { Filho da puta (son of a whore) } \\
\text { Bunda (buttocks) } \\
\text { Buceta (vagina) } \\
\text { Cacete (penis) } \\
\text { Caralho (penis) } \\
\text { Porra (sperm) } \\
\text { Vá tomar no cu (fuck off) }\end{array}$ & $\begin{array}{l}\text { Fuck } \\
\text { Cunt } \\
\text { Bastard } \\
\text { Piss } \\
\text { Sod } \\
\text { Cock } \\
\text { Shit } \\
\text { Prick }\end{array}$ & $\begin{array}{l}\text { Fuck } \\
\text { Shit } \\
\text { Bitch } \\
\text { Asshole } \\
\text { Bastard }\end{array}$ & $\begin{array}{l}\text { Kusobaa (shit grandma) } \\
\text { Chikusho (son of a whore) } \\
\text { Female genitalia and breasts }\end{array}$ & $\begin{array}{l}\text { Puta (whore) } \\
\text { Mierda (faeces) } \\
\text { Coño (vulva) } \\
\text { Joder (fornicate) } \\
\text { Maricon (homosexual) } \\
\text { Cojones (testicles) } \\
\text { Hijo de puta (son of a whore) } \\
\text { Hostia (holy bread) }\end{array}$ & $\begin{array}{l}\text { Kaeft (shut up) } \\
\text { Svin (swine) } \\
\text { Fisse (vulva) } \\
\text { Kusse (vulva) } \\
\text { Pik (penis) } \\
\text { Røv (buttocks) } \\
\text { Pis (piss) } \\
\text { Gylle (animal faeces) } \\
\text { Sgu (by God) }\end{array}$ \\
\hline
\end{tabular}


We recognised coprolalia in nine patients $(28 \%)$, similar to the results reported by others. ${ }^{1117}$ Like others, ${ }^{18}$ we found that the obscene words most often used by patients with and patients without Tourette's syndrome are similar. The frequency of coprolalia in published series of patients with Tourette's syndrome ranges from $4 \%$ in a study of 97 Japanese children ${ }^{19}$ to about $40 \%$ in American, ${ }^{11}$ British, ${ }^{12}$ and Spanish $^{20}$ series. These discrepancies have been explained as resulting from cultural differences among the geographic areas where the patients were studied. The rarity of coprophenomena among the Japanese, for instance, might reflect the decorum of their culture. ${ }^{20}$ This interpretation is challenged, however, by a recent study showing that only $8 \%$ of 112 young American patients with Tourette's syndrome exhibited coprolalia. ${ }^{18}$ The authors suggested that this symptom is rare among young patients, becoming increasingly common as they grow old. The young age of the Japanese population studied by Nomura and Segawa ${ }^{19}$ would explain their findings. It seems, therefore, that the frequency of coprolalia is relatively stable regardless of the ethnic, cultural, and geographic origin of the studied populations, with the exception of young patients. Table 2 shows the lack of phonetic analogies among the obscenities shouted by patients with Tourette's syndrome in different countries. This holds true for languages with a common origin and similar structure, such as Spanish and Portuguese, and even for countries with similar idioms (United States and England). These findings are not consistent with coprolalia simply resulting from the modulation of the air by muscles of the respiratory pathways, as previously suggested..$^{22}$ Our results suggest that coprolalia may represent an expression of disinhibition, thought to play a crucial part in Tourette's syndrome. ${ }^{16}$ According to this hypothesis, as a result of their genetic defect, some patients with Tourette's syndrome become incapable of suppressing the production and vocalisation of obscenities which vary depending on the culture. On the other hand, as the repertoire of basic motor behaviour (blinking, grimacing, etc) and vocalisations (for example, sniffing and coughing) are common to all humans, their release due to lack of inhibition produces similar simple motor and vocal tics.

As in other studies, ${ }^{481116}$ we could show that in our patients Tourette's syndrome is expressed by a combination of motor and behavioural disturbances. Attention deficit and hyperactivity disorder, the most frequent behavioural disorder $(63 \%)$ in the present series, has been identified in $8 \%$ to $80 \%$ of patients with Tourette's syndrome..$^{210111617}$ The onset of attention deficit and hyperactivity disorder usually precedes the development of tics. ${ }^{116}$ This finding is replicated in our study as attention deficit and hyperactivity disorder was noticed 1.3 years earlier than tics. Sleep disorders, obsessive compulsive behaviour, and depression were found in percentages similar to those reported by others. ${ }^{691216}$
The familial nature of Tourette's syndrome, already emphasised by Gilles de la Tourette, ${ }^{2}$ is also supported by our findings of a family history of tics (84\%), obsessive compulsive behaviour (53\%), and attention deficit and hyperactivity disorder (19\%) among the patients studied. In other series, ${ }^{11} 1223$ relatives with tics and attention deficit and hyperactivity disorder have been recognised respectively in $38 \%$ to $56 \%$ and $26 \%$ of patients. Jankovic and Rohaidy, ${ }^{3}$ however, reported a family history of tics in $79 \%$ of their patients, a number similar to ours. It is not clear, however, why the number of patients in our series with relatives displaying obsessive compulsive behaviour is higher than the figure reported by others $(10-28 \%) .{ }^{8}{ }^{23}$ Reasons other than real differences among the studied populations may account for this discrepancy. Variability in diagnostic criteria for obsessive compulsive behaviour may explain the difference. Conversely, our relatively small sample may have concentrated more severe cases. That most obsessive compulsive behaviour family history is related to maternal heritage is consistent with the notion that the Tourette's syndrome gene is expressed by this behavioural abnormality more commonly among women. ${ }^{4}$

Patients with Tourette's syndrome evaluated at a tertiary referral centre such as the FUMG-MDC may present with a more severe disease, not necessarily representative of the general population. In a study of a large kindred with Tourette's syndrome, for example, $37 \%$ of patients with this disorder were unaware of their tics. ${ }^{24}$ None the less, our findings show that regardless of the geographic region, ethnic origin, and cultural background, patients with Tourette's syndrome are similar. This supports the concept that genetic influences are most important in the aetiology of Tourette's syndrome. ${ }^{16}$ However, the part played by environmental factors in its expression should not be overlooked. As we have discussed in the present study, coprophenomena may be influenced by the cultural environment of the patients. Furthermore, twin studies have shown correlation between lower birth weight and greater severity of symptoms of Tourette's syndrome. ${ }^{16}$

1 Task Force on DSM-IV. Diagnostic and statistical manual of mental disorders. 4th ed. Washington, DC: American mental disorders. 4th ed. Wachiatric Association, 1994:101-3.

2 Singer HS, Walkup JT. Tourette syndrome and other tic disorders. Diagnosis, pathophysiology, and treatment. Medicine 1991;70:15-32.

3 Gilles de la Tourette G. Etude sur une affection nerveuse caracterisée par l"incoordination motrice accompagnée d'echolalie et coprolalie. Arch Neurol 1886;9:19-42.

4 Pauls DL, Leckman JF. The inheritance of Gilles de la Tourette's syndrome and associated behaviors: evidence for autosomal dominant transmission. N Engl $\mathcal{F} \mathrm{Med}$ 1986;315:993-7

5 Kerbeshian J, Burd L. Epidemiology and comorbidity. The North Dakota prevalence studies of Tourette syndrome and other developmental disorders. Adv Neurol 1992; 58:67-74.

6 Park S, Como PG, Cui L, Kurlan R. The early course of the Tourette's syndrome clinical spectrum. Neurology 1993;43:1712-15.

7 Apter A, Pauls DL, Bleich A, et al. An epidemiologic study of Gilles de la Tourette's syndrome in Israel. Arch Gen of Gilles de la Tourette'

8 Jankovic J, Rohaidy H. Motor, behavioral and pharmacologic findings in Tourette's syndrome. Can $\mathcal{F}$ Neurol Sci 1987;14:541-6.

9 Burd L, Kerbeshian J, Cook J, Bornhoeft DM, Fisher W. Tourette disorder in North Dakota. Neurosci Biobehav Rev 1988;12:223-8. 
10 Caine ED, McBride MC, Chiverton P, et al. Tourette's syndrome in Monroe County school children. Neurology 1988;38:472-5.

11 Comings DE, Comings BG. Tourette syndrome: clinical and psychological aspects of 250 cases. Am f Hum Genet 1985;37:435-50.

12 Lees AJ, Robertson M, Trimble MR, Murray NMF. A clinical study of Gilles de la Tourette syndrome in the United Kingdom. 7 Neurol Neurosurg Psychiatry 1984; 47:1-8.

13 Fontanari JL, Vaitses VDC. Síndrome de Gilles de la Tourette e múltiplos tiques-estudo clínico de 15 casos e revisão da literatura. Neurobiologia 1986;49. 109-28.

14 Robertson MM, Trimble MR. Gilles de la Tourette syndrome in the Middle East. Report of a cohort and a multiply affected large pedigree. Br f Psychiatry 1991;158 $416-9$.

15 Eapen V, Srinath S. Gilles de la Tourette syndrome in India: two cases. Psychol Rep 1992;70:667-8.

16 Kurlan R. Hypothesis II: Tourette's syndrome is part of a clinical spectrum that includes normal brain development. Arch Neurol 1994;51:1145-50.

17 Robertson MM. The Gilles de la Tourette syndrome: the current status. Br F Psychiatry 1989;154:147-69.

18 Goldenberg $\mathrm{N}$, Brown SB, Weiner W. Coprolalia in younger patients with Gilles de la Tourette syndrome. Mov Disord 1994;9:622-5.

19 Nomura Y, Segawa M. Tourette syndrome in oriental children: Clinical and pathophysiological considerations. Adv Neurol 1982;35:277-83.

20 Lees AJ, Tolosa E. Tics. In: Jankovic J, Tolosa E, eds. Parkinson's disease and movement disorders. 2nd ed. Parkinson's disease and movement disorders.

21 Reuger L, Pakkenberg B, Fog R, Pakkenberg H. Clinical features and long term follow up in 65 patients with
fouger L, Pakkenberg B, Fog R, Pakkenberg $\mathrm{H}$. Clinical Gilles de la Tourette syndrome. $f$ Neurol Neurosurg Psychiatry 1986;49:791-5.

22 Nuwer MR. Coprolalia as an organic symptom. Adv Neurol 1982;35:363-8

23 Kurlan R, Whitmore D, Irvine C, et al. Tourette's syndrome in a special education population: a pilot study involving a single school district. Neurology 1994;44: 699-702.

24 Kurlan R, Behr J, Medved L, et al. Severity of Tourette's syndrome in one large kindred: implications for determination of disease prevalence rate. Arch Neurol 1987;44: $268-9$.

 